\title{
Endogenous estrogen exposure and chronic kidney disease; a 15-year prospective cohort study
}

\author{
Maryam Farahmand ${ }^{1}$, Fahimeh Ramezani Tehrani ${ }^{1 *}$, Davood Khalili' ${ }^{2,3}$, Leila Cheraghi ${ }^{3}$ and Fereidoun Azizi $^{4}$
}

\begin{abstract}
Background: Despite strong evidence demonstrating the role of estrogen as a protective factor for kidney function in women, limited data are available regarding the influence of endogenous estrogen exposure (EEE) on chronic kidney disease (CKD). The present study aimed to assess the incidence of CKD in women with various levels of EEE.

Methods: In a prospective population-based study over a 15-year follow-up, a total of 3043 eligible women aged 30-70 years, participating in Tehran-Lipid and Glucose-Study were recruited and divided into two groups (EEE $<11$ and $E E E ~ \geq 11$ years). EEE calculated based on age at menarche, age at menopause, number and duration of pregnancies, lactation, and duration of oral contraceptive use after excluding the progesterone dominant phase of the menstrual cycle. Cox's proportional hazards model was applied to estimate the hazard ratio of CKD between the study groups, after adjusting for confounders.

Results: The total cumulative incidence rate of CKD was 50.1 per 1000 person years; 95\% Cl: 47.7-52.6); this was $53.9(95 \% \mathrm{Cl}, 50.2-57.8)$ and $47.1(95 \% \mathrm{Cl}, 44.0-50.4)$ per 1000 person years in women with $\mathrm{EEE}<11$ and $\mathrm{EEE} \geq 11$ years, respectively. The model adjusted for age, BMl, smoking, hypertension, and diabetes showed that the hazard ratio (HR) of incidence CKD in women with $E E E<11$ compare to those with $E E E \geq 11$ years in the subgroup of women aged $<45$ years was $2.66(95 \% \mathrm{Cl}, 2.2,3.2)$, whereas, in the subgroup aged $\geq 45$ years, it was $1.22(95 \% \mathrm{Cl}$, 1.04, 1.4).
\end{abstract}

Conclusion: This study shows a higher HR of CKD incidence in women with low EEE levels in their later life. Screening of these women for CKD may be recommended.

Keywords: Endogenous estrogen exposure, Chronic kidney disease (CKD), Menopause, Menarche, Estimated glomerular filtration rate (eGFR)

\section{Background}

The kidney, a powerful endocrine organ, is an important modulator of endocrine function, and the main target for hormonal action [1]. Chronic kidney disease (CKD) can be determined as a persistent injury of the renal parenchyma which causes chronic deterioration of renal

\footnotetext{
* Correspondence: ramezani@endocrine.ac.ir

${ }^{1}$ Reproductive Endocrinology Research Center, Research Institute for Endocrine Sciences, Shahid Beheshti University of Medical Sciences, Tehran, Iran

Full list of author information is available at the end of the article
}

function that may progressively worsen to end-stage kidney disease (ESKD) [1].

Studies show that slower progression of CKD and lower incidence of ESKD in younger women compared to men, and omitting this gender protection after menopause, suggests a role for female hormones [2-4]. While the mechanisms responsible for the protection of kidneys by these hormones, mainly estrogen, are not completely understood, it seems to be due to induced vasodilation in the renal vessels, enhancing the production of nitric oxide

(c) The Author(s). 2021 Open Access This article is licensed under a Creative Commons Attribution 4.0 International License, which permits use, sharing, adaptation, distribution and reproduction in any medium or format, as long as you give appropriate credit to the original author(s) and the source, provide a link to the Creative Commons licence, and indicate if changes were made. The images or other third party material in this article are included in the article's Creative Commons licence, unless indicated otherwise in a credit line to the material. If material is not included in the article's Creative Commons licence and your intended use is not permitted by statutory regulation or exceeds the permitted use, you will need to obtain permission directly from the copyright holder. To view a copy of this licence, visit http://creativecommons.org/licenses/by/4.0/. The Creative Commons Public Domain Dedication waiver (http://creativecommons.org/publicdomain/zero/1.0/) applies to the data made available in this article, unless otherwise stated in a credit line to the data. 
(NO), attenuation of inflammation, and reduction in ischemia mediators [5-7].

It has been shown that estrogen stimulates the release of NO resulting in vasodilation; NO deficiency can be associated with acceleration of kidney injury by reduction of vasodilation and endothelial dysfunction. Estrogen also decreases the synthesis of renin and angiotensinconverting enzyme (ACE) and increases angiotensinogen synthesis [8]. Experimental studies demonstrate that administration of continuous estradiol can prevent glomerulosclerosis and albuminuria [9].

Despite existing strong evidence demonstrating the role of estrogen as a protective factor for kidney function in women, limited data are available regarding the influence of endogenous estrogen exposure (EEE) on chronic kidney disease (CKD); EEE can be calculated based on reproductive factors, including age at menarche, age at menopause, number and duration of pregnancies, lactation, and duration of oral contraceptive use [10]. In this prospective study, we aimed to investigate the incidence and hazard ratio of CKD among women with lower durations of EEE compared to those with higher exposure, after adjustment for known confounders.

\section{Methods}

\section{Subjects \& Study procedure}

Subjects of the present study were recruited from among participants of the Tehran Lipid and Glucose Study (TLGS). This study is an ongoing prospective study, initiated in 1998, to determine the prevalence of noncommunicable disease (NCD) risk factors among 15,000 participants aged $>3$ years. This population was selected from the population of district 13 in Tehran using a multistage stratified cluster random sampling technique. This district was selected mainly due to the high rate of stability; moreover, its age distribution was representative of the overall population in Tehran. After recruitment, all study participants were followed in 3-year intervals. Demographic, habitus, reproductive history, family history, and cardio-metabolic risk factors were assessed through face to face interview at the initiation of the study and throughout the follow ups. A comprehensive physical exam including anthropometric measurements, systolic, and diastolic blood pressures was conducted at baseline and follow ups. Moreover, blood samples were drawn at each visit between 7:00 and 9:00 am after $12 \mathrm{~h}$ of overnight fasting for metabolic assessments. All blood analyses were performed at the TLGS research laboratory on the day of blood collection. The CKD status was identified at the initiation of the study and throughout the follow ups according to the Kidney Disease Outcome Quality Initiative guidelines (K/ DOQI). The details of TLGS was published elsewhere [11].
There were 5226 women, regardless of menopausal status, aged 30-70 years selected for our study. After excluding those with CKD at baseline $(n=1425)$, those with missing data of CKD $(n=97)$, those with missing data on age at menarche $(n=1019)$, the number of remained women was 3141 . We further excluded those with missing data for calculating $\operatorname{EEE}(n=98)$, HRT users $(n=87)$, and those without at least one followup $(n=92)$. Finally, 3043 women remained for the present study.

The study flowchart is presented in Fig. 1.

\section{Measurements}

Using a measuring tape with $0.5-\mathrm{cm}$ accuracy, in a standing position against a wall, without shoes, and with shoulders in a normal position, height was measured. Using an electronic digital weighing scale with $0.1-\mathrm{kg}$ accuracy, while women were minimally clothed, without shoes, weight was measured. Body mass index (BMI) was calculated using dividing weight in kilograms by height in meters squared.

Systolic and diastolic blood pressure (SBP and DBP) was measured twice after a $15 \mathrm{~min}$ rest in a sitting position on the right arm, and the mean was considered as the participants' blood pressure. Weight was measured with individuals minimally clothed, using digital scales (Seca 707: range 0.1-150 kg) and recorded to the nearest $0.1 \mathrm{~kg}$. Height was measured in a standing position, using a tape meter, while shoulders were in normal alignment.

Plasma glucose was measured using an enzymatic colorimetric method with glucose oxidase. Serum concentrations of creatinine $(\mathrm{Cr})$ were tested by kinetic colorimetric Jaffe. The sensitivity of the assay was 0.2 $\mathrm{mg} / \mathrm{dL}$ (range, $18-1330 \mu \mathrm{mol} / \mathrm{L}(0.2-15 \mathrm{mg} / \mathrm{dL}$ ). Reference intervals based on the manufacturer's recommendation was $53-97 \mu \mathrm{mol} / \mathrm{L}(0.6-1.1 \mathrm{mg} / \mathrm{dL})$ in women. Intra-assay and inter-assay CVs were less than $3.1 \%$ at both baseline and follow-up phases. All biochemical assays were performed using commercial kits (Pars Azmoon Inc., Tehran, Iran) by a Selectra 2 autoanalyzer (Vital Scientific, Spankeren, The Netherlands) [12, 13].

\section{Definitions}

Menopause was defined as the absence of menstruation during consecutive12 months according to the World Health Organization definition [14].

According to the Kidney Disease Outcome Quality Initiative guidelines (K/DOQI), CKD is defined as either kidney damage or Glomerular Filtration Rate (GFR) < $60 \mathrm{~mL} / \mathrm{min} / 1.73 \mathrm{~m} 2$ for $>3$ months [15]. In the present study, we estimated GFR using the abbreviated prediction equation, provided by the Modification of Diet in Renal Disease (MDRD) study [16] as follows: 


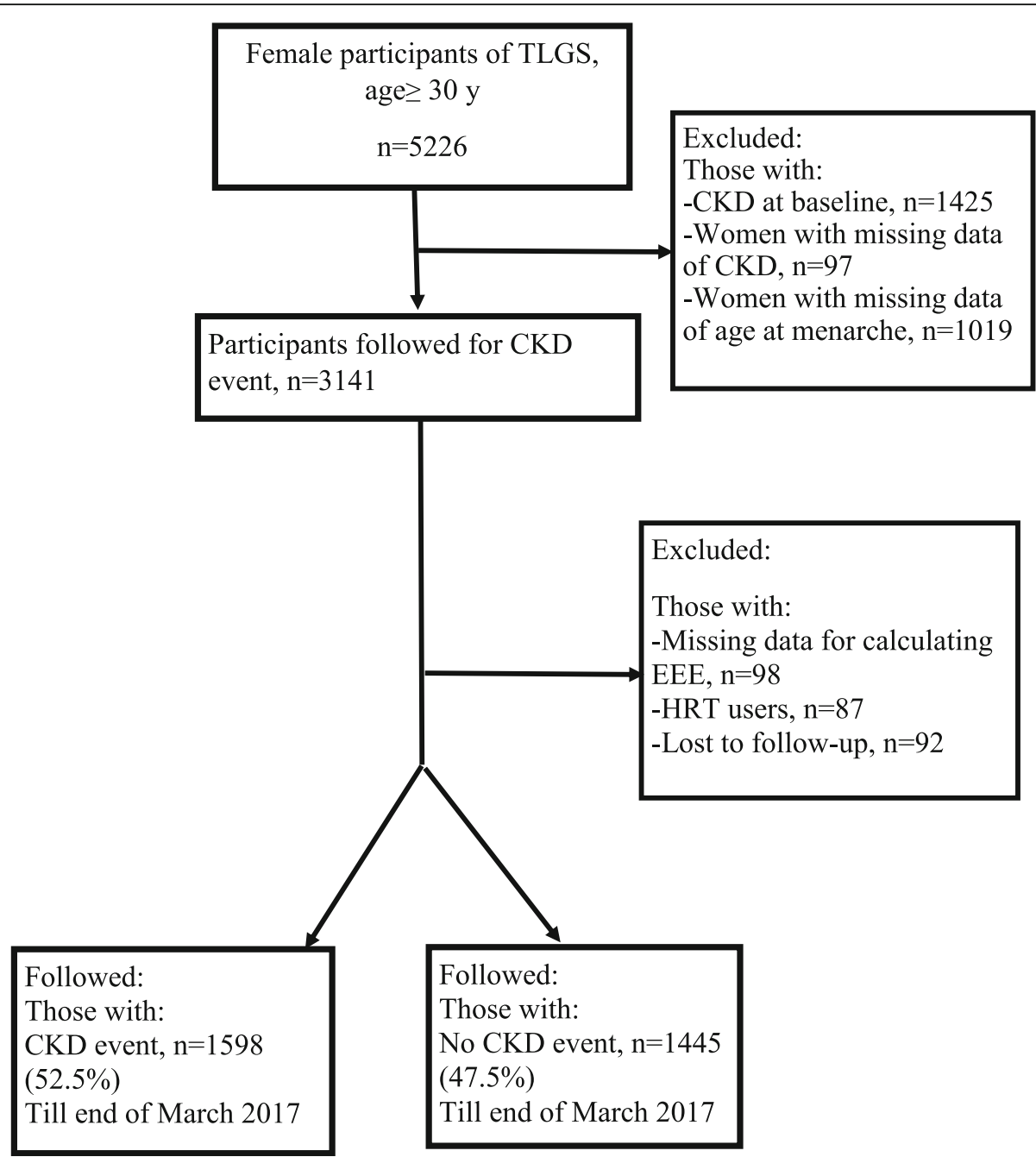

Fig. 1 Study flowchart. Abbreviations: TLGS, Tehran Lipid and Glucose Study; CKD, Chronic Kidney Disease; EEE, Endogenous Estrogen Exposure; HRT, Hormone Replacement Therapy

$$
\begin{aligned}
\mathrm{GFR}= & 186 \times(\mathrm{SCr})^{-1.154} \times(\text { Age })^{-0.203} \times 0.742 \\
& \times(0.742 \text { if female })
\end{aligned}
$$

In this equation, estimated GFR (eGFR) is expressed as $\mathrm{mL} / \mathrm{min}$ per $1.73 \mathrm{~m} 2$ and serum creatinine $(\mathrm{SCr})$ is expressed as $\mathrm{mg} / \mathrm{dL}$; based on the guidelines, we considered CKD as an eGFR $>60 \mathrm{~mL} / \mathrm{min} / 1.73 \mathrm{~m} 2$, occurring at any time during the follow-up period.

Endogenous estrogen exposure (EEE) was defined as the time interval between age at menarche and menopausal age or age at CKD event or end of follow-up, whichever occurred earlier. To consider only E2 dominant of menstrual cycles, we omitted the cumulative durations of progesterone dominant phases of menstrual (only the first 2 weeks, follicular phase, for each menstrual cycle was considered) using as well as those of pregnancies and lactation (assumed 40 weeks for each birth or 20 weeks for each abortion); as a result, EEE is absolutely less than half of the time duration between menarche and menopause.

Hypertension was defined as systolic blood pressure (SBP)/ diastolic blood pressure (SBP) $\geq 140 / 90 \mathrm{mmHg}$ or current treatment for diagnosed hypertension [17]. Diabetes was defined as fasting plasma glucose (FPG) $\geq 7.0$ $\mathrm{mmol} / \mathrm{l}$ or 2 -h post $75 \mathrm{~g}$ glucose load $\geq 11.1 \mathrm{mmol} / \mathrm{l}$ or under current treatment for diagnosed diabetes [18]. Smoking status was categorized as ever smoker (current/ past) or never smoker [19]. Physical activity was measured as the MET value multiplied by the duration of activity in minutes multiplied by the frequency of activity per week. Each activity was weighted via its relative power, referred to as a MET; one MET shows the energy spent for an individual at rest $(1 \mathrm{MET}=3.5 \mathrm{ml} / \mathrm{kg}$. min of oxygen consumption). Energy expending was estimated based on the metabolic equivalent, duration of the activity, and body weight. To get the total weekly leisure time 
energy expending the individual activities values were summed [20].

\section{Statistical analysis}

Results are reported as mean and standard deviation (SD) for continuous variables and number (percentage) for categorical measures. For continuous variables with skewed distribution, the median (inter-quartile range) was calculated. Using the Cubic Spline regression approach, we assessed the knot as 11 years for EEE duration. Furthermore, participants were categorized into two groups according to cut-offs of EEE duration, of $<$ 11 , and $\geq 11$ years. Also, the analysis was repeated by age group $<45$ and $\geq 45$ years at baseline.

Time to event was specified as a time of censoring or date of incidence of CKD or age at menopause, whichever happened first. Participants were censored as a result of death, loss to follow-up, or the end of the observation duration. For censored subjects or for those moving out of the area and thus lost to followup, the most recent follow-up visit was used. "Time" was considered as the interval between the first and the last follow-up dates. The event date for CKD was defined as midtime between the dates of the followup visit at which the CKD was recognized for the first time, and the last follow-up visit before diagnosis. The incidence rate of CKD was calculated per 1000 person years of follow up between those with $\mathrm{EEE}<11$ and $\mathrm{EEE} \geq 11$ years. Cumulative incidence of CKD was measured via the Kaplan-Meier method and compared between these 2 groups, using the log-rank statistic.

Cox proportional hazards regression model was used to estimate the hazard ratio (HR) and 95\% confidence interval $(\mathrm{CI})$ for the group with $\mathrm{EEE}<11$ years compared to those with EEE $\geq 11$ years. The Cox model was adjusted for age, BMI, smoking, hypertension, and diabetes. The proportional hazards assumption of the Cox models was assessed graphically and was satisfied. The Statistical Package for Social Sciences (SPSS version 20; SPSS Inc.) and STATA software (version 13; STATA Inc.) was used for data analysis.

Table 1 Characteristics of subjects in groups by the cut-off of exposure durations of endogenous estrogen

\begin{tabular}{|c|c|c|c|}
\hline \multirow[b]{2}{*}{ Variables } & \multicolumn{3}{|c|}{ Duration of endogenous estrogen exposure } \\
\hline & $\begin{array}{l}\text { Group } 1 \\
<11 \text { years }\end{array}$ & $\begin{array}{l}\text { Group } 2 \\
\geq 11 \text { years }\end{array}$ & Total \\
\hline Subjects (no)* & $1429(47.0)$ & 1614(53.0) & $3043(100)$ \\
\hline Age(years) ${ }^{* *}$ & $39.2 \pm 8.8$ & $46.6 \pm 9.8$ & $43.1 \pm 10.1$ \\
\hline Menarcheal age(years) ${ }^{* *}$ & $13.7 \pm 1.4$ & $13.5 \pm 1.5$ & $13.6 \pm 1.5$ \\
\hline Body mass index $\left(\mathrm{kg} / \mathrm{m}^{2}\right) * *$ & $28.1 \pm 4.6$ & $28.5 \pm 4.8$ & $28.3 \pm 4.7$ \\
\hline Hypertension (yes)* & 195(13.8) & $425(26.8)$ & $620(20.6)$ \\
\hline Antihypertensive drug use * & $60(4.2)$ & 150(9.3) & 210(6.9) \\
\hline Angiotensin-converting-enzyme inhibitor use* & $9(0.6)$ & $19(1.2)$ & $28(0.9)$ \\
\hline Diabetes type $2^{*}$ & $110(7.9)$ & 238(15.1) & $348(11.7)$ \\
\hline Anti-diabetes type 2 drug use* & $39(2.7)$ & $92(5.7)$ & $131(4.3)$ \\
\hline Ever Smoker (yes) * & $82(5.8)$ & $72(4.5)$ & 154(5.1) \\
\hline eGFR $\left(\mathrm{ml} / \mathrm{min}\right.$ per $\left.1.73 \mathrm{~m}^{2}\right)$ & $71.9 \pm 8.5$ & $70.7 \pm 8.0$ & $71.3 \pm 8.3$ \\
\hline Creatinine $(\mathrm{mg} / \mathrm{dl})^{* *}$ & $0.94 \pm 0.08$ & $0.92 \pm 0.08$ & $0.93 \pm 0.06$ \\
\hline Physical activity(MET- min/week) ${ }^{* *}$ & $1639 \pm 2350.5$ & $1577.7 \pm 2049.4$ & $1606.7 \pm 2195.2$ \\
\hline Menopause status (yes)* & $345(24.1)$ & 1420(88.0) & 1765(58) \\
\hline Menopausal age(years) ** & $44.1 \pm 6.6$ & $50.0 \pm 4.0$ & $48.8 \pm 5.2$ \\
\hline Total duration of pregnancies (years)** & $2.72 \pm 1.4$ & $3.09 \pm 1.5$ & $2.90 \pm 1.5$ \\
\hline Total duration of hormonal contraceptive use (years) ${ }^{* *}$ & $0.55 \pm 1.0$ & $0.47 \pm 0.5$ & $0.53 \pm 0.9$ \\
\hline Total duration of breastfeeding (weeks) $* *$ & $4.35 \pm 2.6$ & $2.25 \pm 1.6$ & $3.7 \pm 2.5$ \\
\hline Follow-up time (years) ${ }^{* * *}$ & $15.5(12.2,16.5)$ & $15.6(12.5,16.6)$ & $15.6(12.4,16.6)$ \\
\hline
\end{tabular}

Note: ANOVA test, Mann-Whitney test, and Chi-square test were used as appropriate

* Number and percentage

** Mean \pm SD

***Median (Interquartile range)

Note: eGFR estimated glomerular filtration rate; Body mass index\& age are presented at baseline; Total duration of hormonal contraceptive use was calculated only in contraceptive users. Menopause status was assessed during follow-up or before event or censoring. Menopausal age was calculated among participants who had reached menopause. MET, metabolic equivalent task

Note: Group1: Endogenous estrogen exposure duration < 11 years, group, 2: Endogenous estrogen exposure duration $\geq 11$ years 


\section{Results}

Characteristics of the study subjects according to the EEE cutoff value of 11 years are shown in Table 1. Mean \pm SD age and menarcheal age of study subjects were $43.1 \pm 10.1$, and $13.6 \pm 1.5$ years, respectively.

The median and 25-75\%follow-up time for the current analysis was 15.6 and 12.4, 16.6 years. The overall incidence of CKD was 50.1 per 1000 person years (95\%CI: 47.7-52.6). It was 53.9(95\%CI: 50.2-57.8), and 47.1(95\%CI: 44.0-50.4) per 1000 person years in women with $\mathrm{EEE}<11$ and EEE $\geq$ 11 years, respectively. As a result of subgrouping the participants into two age groups ( $<45$, and $\geq 45$ years), in those aged $<45$, the incidence of CKD was 45.6 (95\%CI: 41.9, 49.7) per 1000 person years in women with $\mathrm{EEE}<11$ years. In the recent age group, the incidence of CKD was 22.4(95\%CI: $19.6,25.5)$ per 1000 person years in women with $\mathrm{EEE} \geq 11$ years. In those aged $\geq 45$, the incidence of CKD was 92.5 (95\%CI: 81.3, 105.2) per 1000 person years in women with $\mathrm{EEE}<11$ years. In the same age group, the incidence of CKD was 78.9 (95\%CI: 72.9, 85.5) per 1000 person years in women with EEE $\geq 11$ years (Table 2).

Kaplan-Meier cumulative incidence of CKD was statistically different between women with $\mathrm{EEE}<11$ and those with EEE $\geq 11$ years, among total $(p=0.002)$ and two age groups $(p<0.001$ and $p=0.03)$ (Fig. 2).
As the interaction between age groups and EEE duration was statistically significant $(P<0.001)$; so the Cox regression model was conducted separately in age groups. In the unadjusted model, the hazard of CKD in women with $\mathrm{EEE}<11$ years was $17 \%$ more than those women with EEE $\geq 11$ years (95\% CI: 1.1,1.3; $p=0.002$ ). The adjusted model showed that the hazard of CKD incidence in women with $\mathrm{EEE}<11$ years compared to those with $\geq 11$ years was 4.0 fold (95\% CI: $2.5,6.3 ; p<0.001$ ).

In the subgroup of women aged $<45$, the hazard of CKD incidence in women with EEE $<11$ years compared to those women with $\mathrm{EEE} \geq 11$ years was 2.2 fold (95\% CI:1.9,2.5; p $<0.001)$, in the unadjusted model. This HR is changed to $2.7(95 \% \mathrm{CI}: 2.2,3.2 ; \mathrm{p}<0.001)$ after adjustment for age, BMI, smoking, hypertension, and diabetes.

In the subgroup of women aged $\geq 45$, the hazard of CKD incidence in women with $\mathrm{EEE}<11$ years was $17 \%$ (HR: 1.17; 95\% CI:1.0,1.4; $p=0.03)$ more than those women with EEE $\geq 11$ years, in the unadjusted model. This HR is changed to $1.22(95 \% \mathrm{CI}: 1.04,1.4 ; p=0.01)$ after adjustment for the above-mentioned variables (Table 2 ).

\section{Discussion}

To the best of our knowledge, this is the first study reporting the effects of endogenous estrogen exposure

Table 2 Unadjusted and multiple adjusted hazard ratios of incident CKD by cut off value of 11 years for the duration of EEE and subgroups of age at baseline

\begin{tabular}{|c|c|c|c|c|c|}
\hline \multirow{2}{*}{$\begin{array}{l}\text { Endogenous } \\
\text { estrogen exposure } \\
\text { duration }\end{array}$} & \multirow{2}{*}{$\begin{array}{l}\text { Crude number of incident CKD } \\
\text { (incident rate per } 1000 \text { person years) } \\
(95 \% \mathrm{Cl})\end{array}$} & \multicolumn{2}{|l|}{ Unadjusted } & \multicolumn{2}{|l|}{ Adjusted* } \\
\hline & & $\mathrm{HR}(95 \% \mathrm{Cl})$ & $P$ value & HR $(95 \% \mathrm{Cl})$ & $P$ value \\
\hline \multicolumn{6}{|l|}{ Total } \\
\hline \multicolumn{6}{|l|}{$N=3043$} \\
\hline Group1 (< 11 years) & 769 (53.9) & $1.17(1.1,1.3)$ & 0.002 & $4.0(2.5,6.3)$ & $<0.001$ \\
\hline$N=1429$ & $(50.2,57.8)$ & & & & \\
\hline Group 2 ( $\geq 11$ years) & $829(47.1)$ & Ref & Ref & Ref & Ref \\
\hline$N=1614$ & $(44.0,50.4)$ & & & & \\
\hline \multicolumn{6}{|l|}{$<45$ years } \\
\hline \multicolumn{6}{|l|}{$N=1860$} \\
\hline Group1 (< 11 years) & $537(45.6)$ & $2.2(1.9,2.5)$ & $<0.001$ & $2.7(2.2,3.2)$ & $<0.001$ \\
\hline$N=1120$ & $(41.9,49.7)$ & & & & \\
\hline Group 2 ( $\geq 11$ years) & $222(22.4)$ & Ref & Ref & Ref & Ref \\
\hline$N=740$ & $(19.6,25.5)$ & & & & \\
\hline \multicolumn{6}{|l|}{$\geq 45$ years } \\
\hline \multicolumn{6}{|l|}{$N=1183$} \\
\hline Group1(< 11 years) & $232(92.5)$ & $1.17(1.0,1.4)$ & 0.03 & $1.22(1.04,1.4)$ & 0.01 \\
\hline$N=309$ & $(81.3105 .2)$ & & & & \\
\hline Group 2 ( $\geq 11$ years) & 607 (78.9) & Ref & Ref & Ref & Ref \\
\hline$N=874$ & $(72.9,85.5)$ & & & & \\
\hline
\end{tabular}

Note: $\mathrm{Cl}$, Confidence interval; $\mathrm{HR}$, Hazard ratio

Abbreviations: CKD chronic kidney disease, EEE endogenous estrogen exposure

*Adjusted for baseline age and body mass index, smoking, hypertension, diabetes type 2 
A

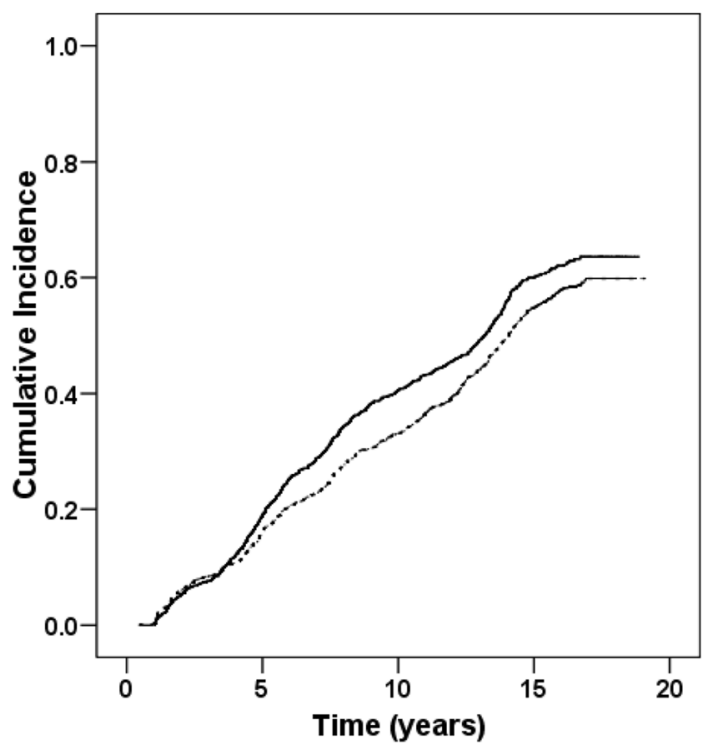

B

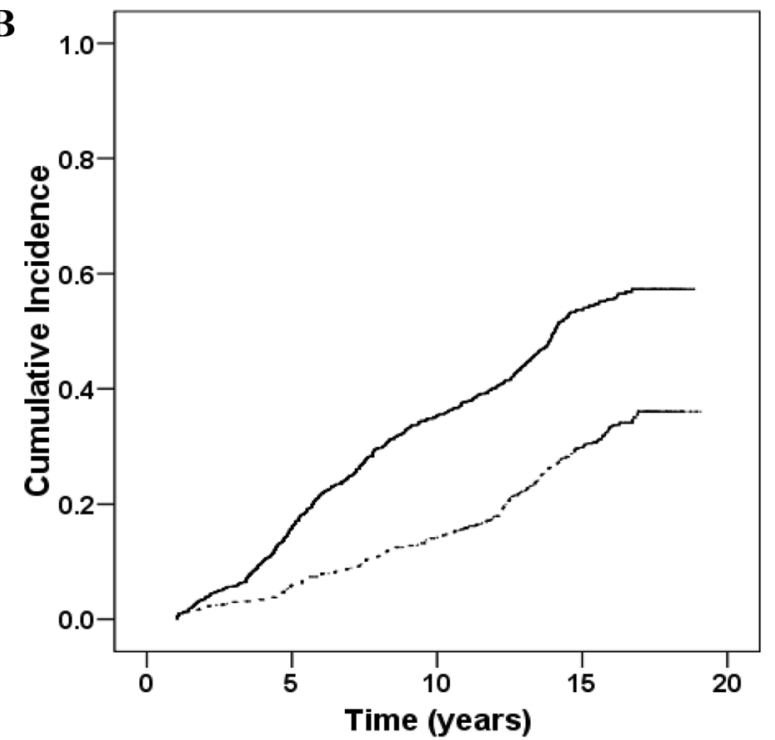

C

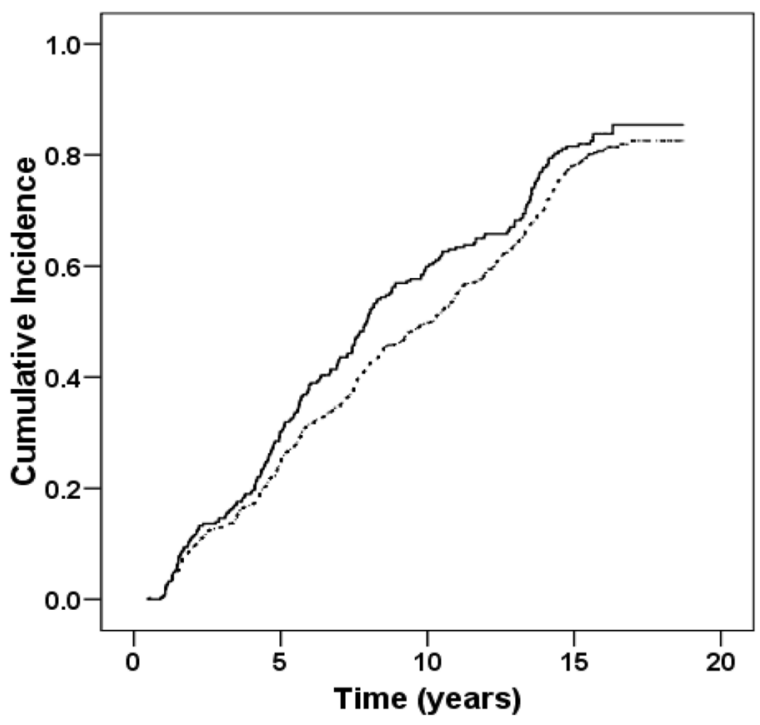

Fig. 2 Kaplan-Meier cumulative estimates of incidence rates of CVD in subjects, according to the cutoff of endogenous estrogen exposure duration. A: Total of participants; B: Participants aged < 45 years; C: Participants aged $\geq 45$ years. Note: Endogenous estrogen exposure duration< 11 years (solid line), and Endogenous estrogen exposure duration $\geq 11$ years (dotted line)

on chronic kidney disease We found that after adjustment for all influencing variables, the hazard ratio of CKD among those women with $>11$ years of EEE is fourfold (95\% CI: 2.5,6.3, $P<0.001$ ) that of those with $\geq 11$ years of exposure. An adverse effect even stronger among those women aged $<452.7(95 \% \mathrm{CI}: 2.2,3.2)$ vs. $1.22(1.04,1.4)$ in women aged $\geq 45$ years was observed.

There is controversy about the impact of sex hormones on renal function and disease as well as the gender dependency of CKD; the lower susceptibility of women could be due to the absence of testosterone or the presence of estrogen [21] via elevated synthase production nitric oxide in kidneys [22-24].
It has been shown that estrogen may affect kidney function through several pathways including improved metabolism, the selectivity of Angiotensin Type 2 (AT2) receptor signaling, diminished oxidative stress, and differential renin-angiotensin system (RAS) [25]. There is some evidence that NO deficiency can be associated with acceleration of renal injury, based on receptors that impaired vasodilation and endothelial dysfunction have been reported in CKD [5].

Estradiol may improve kidney function by suppressing the transforming growth factor $\beta-1$ (TGF- $\beta-1$ ) that induces mesangial cell apoptosis [26], and enhancing mesangial cell growth [27] by up-regulating NO synthase 
activity via vascular agents; furthermore, estrogen receptor $\alpha$ that largely expressed in the kidneys [28], has the opposite effect of apoptosis in podocytes [29] and also acts as a regulator of renal sodium and potassium homeostasis and the renin-angiotensin pathway [30]. Several studies have reported the anti-apoptotic and anti-fibrotic effects of endogenous estrogens in the kidney [2, 31-33], which may partly explain the protective effect of estrogen on the kidney. Estrogen may also have kidney protective effects by reducing renin and angiotensin-converting enzyme (ACE) synthesis and increasing angiotensinogen synthesis [8]. Also, estrogen acts as a mediator by reducing arterial pressure via signaling the AT2 receptor and ACE2 [25]. Animal studies reveal the acceleration of progression of glomerulosclerosis due to estrogen shortage, resulting in diminished glomerular permeability and ischemiareperfusion damage [2, 31-33].

Endogenous estrogen has been introduced as an important influential factor in NCDs (such as CKD) for its promotion of angiogenesis and vasodilation and decreasing of reactive oxygen species, oxidative stress, and fibrosis [25]. Shorter durations of EEE have been reported to be associated with increased risk of osteoporosis, total mortality, venous thromboembolism, and CVD [10, 19]. However, to the best of our knowledge, the association between EEE and CKD has not been reported before.

We found that the impact of the duration of EEE on CKD among younger women is even stronger than in older counterparts, an important finding with high clinical utility given the higher morbidity and mortality of younger women with CKD [35].In addition to early menopause or late age at menarche, other physiological situations such as increased parity and longer duration of lactation may result in a decrease of EEE. Furthermore, pathologic causes of low estrogen levels in young women including excessive exercise, eating disorders, and low-functioning pituitary gland needs to be considered [34, 36-38].

However, with aging, this association weakens, possibly due to overexpression of other known risk factors of CKD such as diabetes and hypertension [39].

This study is strengthened by the use of a comprehensive population-based data set with a long follow-up, large sample size, and precise estimation of CKD and influential factors, which enabled us to perform survival analysis, and adjust for the most important potential confounders; however, it does have some limitations. The main one is, as in most epidemiologic studies [ 1 , 40], we have not repeated $\mathrm{Cr}$ measurements within 3 months to confirm a chronic reduction in GFR. Second, recall bias for some components that have been used for calculation of EEE; however, repeating these measurements every 3 years may reduce the risk of this bias. Although we tried to adjust our results for major known confounders for which data were available, other potentially influencing factors such as diet have not been considered.

\section{Conclusion}

Our findings showed that a lower duration of endogenous estrogen exposure especially among reproductive age women can be considered as a risk factor for CKD, and the early diagnosis of this susceptible group may improve their short-term and long-term morbidities.

\section{Abbreviations}

EEE: Endogenous estrogen exposure; CKD: Chronic kidney disease; eGFR: estimated glomerular filtration rate; ESKD: End-stage kidney disease; NO: Nitric oxide; ACE: Angiotensin-converting enzyme; TLGS: Tehran Lipid and Glucose Study; NCD: Non-communicable Disease; CVD: Cardiovascular disease; SCr: Serum creatinine; KJDOQI: Kidney Disease Outcome Quality Initiative guidelines; MDRD: Modification of Diet in Renal Disease; FPG: Fasting plasma glucose; SBP: Systolic blood pressure; DBP: Diastolic blood pressure; SD: Standard deviation; Cl: Confidence interval; AT2: Angiotensin Type 2; RAS: Renin-angiotensin system

\section{Acknowledgments}

We are beholden to all the study participants for the substantial time and effort given to our study. Thanks are also due to the research staff at the TLGS Unit and personnel of the Endocrine Research Laboratory. The authors wish to acknowledge Ms. Niloofar Shiva for critical editing of English grammar and syntax of the manuscript.

\section{Authors' contributions}

MF contributed to the study design and execution, data analysis, manuscript drafting, and critical discussion. FRT contributed to the study design and execution, data analysis, manuscript drafting, and critical discussion. DK contributed to the study design, and data analysis, and manuscript drafting. LC contributed to the data analysis. FA contributed to the study design and execution and manuscript drafting. All authors have read and approved the manuscript.

\section{Funding}

This study was supported by the Research Institute for Endocrine Sciences (No.1397.284). The funding body has no role in the design of the study and collection, analysis, and interpretation of data and in writing the manuscript.

\section{Availability of data and materials}

The datasets generated and/or analyzed during the current study are not publicly available due to confidentiality considerations.

\section{Declarations}

Ethics approval and consent to participate

The medical ethics committee of this institute approved the study proposal (IR.SBMU.ENDOCRINE.REC.1397.284) and was in adherence with the

Declaration of Helsinki and written informed consent was obtained from all participants.

\section{Consent for publication}

Informed consent for publication was obtained from all participants.

\section{Competing interests}

The authors declare that they have no conflict of interest.

\section{Author details}

${ }^{1}$ Reproductive Endocrinology Research Center, Research Institute for Endocrine Sciences, Shahid Beheshti University of Medical Sciences, Tehran, Iran. ${ }^{2}$ Prevention of Metabolic Disorders Research Center, Research Institute for Endocrine Sciences, Shahid Beheshti University of Medical Sciences, Tehran, Iran. ${ }^{3}$ Department of Epidemiology and Biostatistics, Research Institute for Endocrine Sciences, Shahid Beheshti University of Medical 
Sciences, Tehran, Iran. ${ }^{4}$ Endocrine Research Center, Research Institute for Endocrine Sciences, Shahid Beheshti University of Medical Sciences, Tehran, Iran.

Received: 4 July 2020 Accepted: 18 July 2021

Published online: 04 August 2021

\section{References}

1. Akchurin M. Chronic kidney disease and dietary measures to improve outcomes. Pediatr Clin. 2019;66(1):247-67. https://doi.org/10.1016/.jpcl.2018.09.007.

2. Silbiger S, Neugarten J. Gender and human chronic renal disease. Gend Med. 2008;5(Suppl A):S3-s10.

3. Kummer S, von Gersdorff G, Kemper MJ, Oh J. The influence of gender and sexual hormones on incidence and outcome of chronic kidney disease. Pediatr Nephrol. 2012;27(8):1213-9. https://doi.org/10.1007/s00467-011-1963-1.

4. Coggins $\mathrm{CH}$, et al. Differences between women and men with chronic renal disease. Nephrol Dial Transplant. 1998;13(6):1430-7. https://doi.org/10.1093/ ndt/13.6.1430

5. Baylis C. Nitric oxide deficiency in chronic kidney disease. Am J Physiol Ren Physiol. 2008;294(1):F1-9. https://doi.org/10.1152/ajprenal.00424.2007.

6. Guetta V, Quyyumi AA, Prasad A, Panza JA, Waclawiw M, Cannon RO III. The role of nitric oxide in coronary vascular effects of estrogen in postmenopausal women. Circulation. 1997;96(9):2795-801. https://doi.org/1 0.1161/01.CIR.96.9.2795.

7. Chen Z, Yuhanna IS, Galcheva-Gargova Z, Karas RH, Mendelsohn ME, Shaul PW. Estrogen receptor alpha mediates the nongenomic activation of endothelial nitric oxide synthase by estrogen. J Clin Invest. 1999;103(3):4016. https://doi.org/10.1172/JCl5347.

8. Cobo G, Hecking M, Port FK, Exner I, Lindholm B, Stenvinkel P, et al. Sex and gender differences in chronic kidney disease: progression to end-stage renal disease and haemodialysis. Clin Sci. 2016;130(14):1147-63. https://doi.org/1 $0.1042 / C S 20160047$.

9. Catanuto P, Doublier S, Lupia E, Fornoni A, Berho M, Karl M, et al. 17 betaestradiol and tamoxifen upregulate estrogen receptor beta expression and control podocyte signaling pathways in a model of type 2 diabetes. Kidney Int. 2009;75(11):1194-201. https://doi.org/10.1038/ki.2009.69.

10. de Kleijn MJ, van der Schouw Y, Verbeek AL, Peeters PH, Banga JD, van der Graaf $Y$. Endogenous estrogen exposure and cardiovascular mortality risk in postmenopausal women. Am J Epidemiol. 2002;155(4):339-45. https://doi. org/10.1093/aje/155.4.339.

11. Azizi F, Zadeh-Vakili A, Takyar M. Review of rationale, design, and initial findings: Tehran Lipid and Glucose Study. Int J Endocrinol Metab. 2018;16(4 Suppl).

12. Hosseinpanah F, et al. High prevalence of chronic kidney disease in Iran: a large population-based study. BMC Public Health. 2009;9(1):1-8.

13. Azizi $F$, et al. Prevention of non-communicable disease in a population in nutrition transition: Tehran lipid and glucose study phase II. Trials. 2009; 10(1):5. https://doi.org/10.1186/1745-6215-10-5.

14. WHO. Research on the menopause: Word Health Organization, G; 1999.

15. National Kidney Foundation. K/DOQI clinical practice guidelines for chronic kidney disease: evaluation, classification, and stratification. Am J Kidney Dis. 2002;39(2 Suppl 1):S1-266.

16. Levey AS, Bosch JP, Lewis JB, Greene T, Rogers N, Roth D. A more accurate method to estimate glomerular filtration rate from serum creatinine: a new prediction equation. Modification of diet in renal disease study group. Ann Intern Med. 1999; 130(6):461-70. https:/doi.org/10.7326/0003-4819-130-6-199903160-00002

17. Lenfant C, Chobanian AV, Jones DW, Roccella EJ, Joint National Committee on the Prevention, Detection, Evaluation, and Treatment of High Blood Pressure. Seventh report of the joint National Committee on the prevention, detection, evaluation, and treatment of high blood pressure (JNC 7): resetting the hypertension sails. Hypertension. 2003;41(6):1178-9. https://doi. org/10.1161/01.HYP.0000075790.33892.AE

18. American Diabetes Association. Report of the expert committee on the diagnosis and classification of diabetes mellitus. Diabetes Care. 2003;26(Suppl 1):S5-20.

19. Farahmand M, Ramezani Tehrani F, Khalili D, Cheraghi L, Bahri Khomami M, Azizi F. Association between duration of endogenous estrogen exposure and cardiovascular outcomes: a population - based cohort study. Life Sci. 2019:221:335-40. https://doi.org/10.1016/.lffs.2019.02.020.

20. Momenan AA, Delshad M, Mirmiran P, Ghanbarian A, Azizi F. Leisure time physical activity and its determinants among adults in Tehran: Tehran lipid and glucose study. Int J Prev Med. 2011;2(4):243-51.
21. Reckelhoff JF, Samson WK. Sex and gender differences in cardiovascular renal and metabolic diseases. Am J Phys Regul Integr Comp Phys. 2015; 309(9):R1057-9. https://doi.org/10.1152/ajpregu.00417.2015.

22. Forte P, Kneale BJ, Milne E, Chowienczyk PJ, Johnston A, Benjamin N, et al. Evidence for a difference in nitric oxide biosynthesis between healthy women and men. Hypertension. 1998;32(4):730-4. https://doi.org/10.1161/ 01.HYP.32.4.730

23. Neugarten J, Ding Q, Friedman A, Lei J, Silbiger S. Sex hormones and renal nitric oxide synthases. J Am Soc Nephrol. 1997;8(8):1240-6. https://doi.org/1 $0.1681 /$ ASN.V881240

24. Xiao S, Gillespie DG, Baylis C, Jackson EK, Dubey RK. Effects of estradiol and its metabolites on glomerular endothelial nitric oxide synthesis and mesangial cell growth. Hypertension. 2001;37(2):645-50. https://doi.org/1 0.1161/01.HYP.37.2.645.

25. Park YJ, Kim JM. Klotho and postmenopausal hormone replacement therapy in women with chronic kidney disease. J Menopausal Med. 2018;24(2):7580. https://doi.org/10.6118/jmm.2018.24.2.75.

26. Dixon A, Maric C. 17ß-estradiol attenuates diabetic kidney disease by regulating extracellular matrix and transforming growth factor- $\beta$ protein expression and signaling. Am J Physiol Renal Physiol. 2007;293(5):F1678-90. https://doi.org/10.1152/ajprenal.00079.2007.

27. Petrica L, Gluhovschi C, Velciov S. Chronic kidney disease and the involvement of estrogen hormones in its pathogenesis and progression. Rom J Intern Med. 2012;50(2):135-44.

28. Potier $\mathrm{M}$, et al. Expression and regulation of estrogen receptors in mesangial cells: influence on matrix metalloproteinase-9. J Am Soc Nephrol. 2001;12(2):241-51. https://doi.org/10.1681/ASN.V122241.

29. Kummer S, Jeruschke S, Wegerich LV, Peters A, Lehmann P, Seibt A, et al. Estrogen receptor alpha expression in podocytes mediates protection against apoptosis in-vitro and in-vivo. PLoS One. 2011;6(11):e27457. https:// doi.org/10.1371/journal.pone.0027457.

30. Tremblay AM, Dufour $C R$, Ghahremani $M$, Reudelhuber $T L$, Giguère $V$. Physiological genomics identifies estrogen-related receptor a as a regulator of renal sodium and potassium homeostasis and the renin-angiotensin pathway. Mol Endocrinol. 2010;24(1):22-32. https://doi.org/10.1210/me.2009-0254.

31. Lim VS, et al. Ovarian function in chronic renal failure: evidence suggesting hypothalamic anovulation. Ann Intern Med. 1980;93(1):21-7. https://doi. org/10.7326/0003-4819-93-1-21.

32. Elliot SJ, Berho M, Korach K, Doublier S, Lupia E, Striker GE, et al. Genderspecific effects of endogenous testosterone: female alpha-estrogen receptor-deficient C57BI/6J mice develop glomerulosclerosis. Kidney Int. 2007;72(4):464-72. https://doi.org/10.1038/s..ki.5002328

33. Hutchens MP, Fujiyoshi T, Komers R, Herson PS, Anderson S. Estrogen protects renal endothelial barrier function from ischemia-reperfusion in vitro and in vivo. Am J Physiol Renal Physiol. 2012;303(3):F377-85. https://doi. org/10.1152/ajprenal.00354.2011.

34. Gargus E, Deans R, Anazodo A, Woodruff TK. Management of primary ovarian insufficiency symptoms in survivors of childhood and adolescent cancer. J Natl Compr Cancer Netw. 2018;16(9):1137-49. https://doi.org/10. 6004/jnccn.2018.7023.

35. Kumar S, Bogle R, Banerjee D. Why do young people with chronic kidney disease die early? World J Nephrol. 2014;3(4):143-55. https://doi.org/10.552 7/wjn.v3.i4.143

36. Kossman DA, Williams NI, Domchek SM, Kurzer MS, Stopfer JE, Schmitz KH Exercise lowers estrogen and progesterone levels in premenopausal women at high risk of breast cancer. J Appl Physiol. 2011;111(6):1687-93. https://doi.org/10.1152/japplphysiol.00319.2011.

37. Li E, Tsang L, Lui S. Menstrual cycle and voluntary food intake in young Chinese women. Appetite. 1999:33(1):109-18. https://doi.org/10.1006/appe.1999.0235.

38. Shufelt CL, Torbati T, Dutra E. Hypothalamic amenorrhea and the long-term health consequences. In: Seminars in reproductive medicine: NIH Public Access; 2017.

39. Islam TM, Fox CS, Mann D, Muntner P. Age-related associations of hypertension and diabetes mellitus with chronic kidney disease. BMC Nephrol. 2009;10(1):17. https://doi.org/10.1186/1471-2369-10-17.

40. Cheung $\mathrm{KL}$, et al. Menopausal symptoms in women with chronic kidney disease. Menopause. 2015;22(9):1006.

\section{Publisher's Note}

Springer Nature remains neutral with regard to jurisdictional claims in published maps and institutional affiliations. 